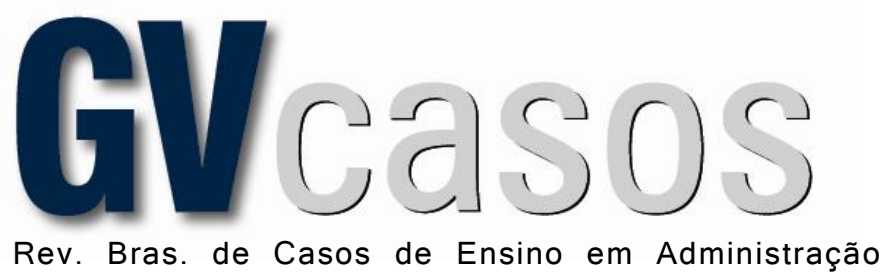

DOI: http://dx.doi.org/10.12660/gvcasosv11n2c13

\title{
UMA MÃO LAVA A OUTRA: DESAFIOS EM PARTICIPAÇÃO SOCIAL ${ }^{1}$ One hand washes the other: challenges in society participation
}

\author{
Júlio CESAR ANDRAde DE ABREU - jandrade0@ gmail.com \\ Universidade Federal Fluminense - Volta Redonda, RJ, Brasil
}

CAMILA DA Silva INOCENCIO - camilainocencio@id.uff.br

Universidade Federal Fluminense - Volta Redonda, RJ, Brasil

Submissão: 27/11/2020 | Aprovação: 25/08/2021

\begin{abstract}
Resumo
Este caso aborda o dilema vivenciado por Mirella, presidente da Associação de Moradores Amoceu, que vivenciou o processo de ascensão de experiências participativas no bairro Céu, conhecido por práticas clientelistas e individualistas nas relações entre moradores e líderes do bairro antes de sua gestão. Como exemplo prático, este caso baseou-se no Orçamento Participativo Digital (OPD) do município. Na tentativa de mitigar os conflitos, que podem dificultar a plena participação da comunidade, ela busca enfrentar o desafio de externar o quanto os processos de participação social são importantes. A presidente vê-se em uma circunstância em que a cooperação mútua aparenta ser a solução.
\end{abstract}

Palavras-chave: clientelismo, participação social, democracia participativa.

\begin{abstract}
This case addresses the dilemma experienced by Mirella, president of the AMOCEU Residents Association, who experienced the ascension process of participatory experiences in the Céu neighborhood, known for clientelist and individualistic practices in the relations between residents and neighborhood leaders before her administration. As a practical example, this case was based on the municipality's Digital Participatory Budget (OPD). In an attempt to mitigate conflicts, which can make it difficult for the community to fully participate, it seeks to face the challenge of expressing how important social participation processes are. The president finds herself in a circumstance where mutual cooperation appears to be the solution.
\end{abstract}

Keywords: clientelism, social participation, participatory democracy.

\section{Introdução}

Em janeiro de 2017, Mirella comemorava a entrega de seu diploma de Bacharel em Administração Pública. Havia esperado ansiosamente por esse dia durante os quatro anos de graduação. Além disso, havia estagiado durante três anos na Secretaria de Planejamento de seu município. Próximo ao fim dessa fase, Mirella resolveu trilhar novos caminhos, e assumiu a posse de sua primeira gestão como presidente da Associação de Moradores no bairro Céu (Amoceu), local onde nasceu e foi criada.

Desde muito nova, Mirella acompanhava as reuniões da Amoceu junto de seu pai. Vivenciou a liderança dele durante longos anos. Por ser pautada em relações de confiança, a gestão de Sr.

${ }^{1}$ Os autores agradecem o apoio do $\mathrm{CNPq}$ 
Antônio só chegou ao fim devido ao seu falecimento. Como era de se esperar, de início, os moradores desconfiaram da disposição apresentada por Mirella em representá-los.

Para receber o voto de confiança na eleição, precisou do apoio de antigos moradores, conhecidos no bairro por suas habilidades em formar opiniões. Um deles era dona Luísa, uma das principais apoiadoras de seu pai durante toda a gestão passada, que tem um papel importante na dinâmica coletiva do Céu e seus moradores.

Tão logo assumiu o novo posto, Mirella marcou a primeira reunião. Imaginou que seu empoderamento e conhecimento adquirido por meio da formação acadêmica seriam capazes de demonstrar que, na atual gestão, os impasses seriam resolvidos de modo distinto da antiga gestão, e que as relações seriam igualitárias. Para ela, a cooperação mútua que é criada em locais como as Associações de Moradores tem papel fundamental para fortalecer a democracia, tornando mais participativo e responsável o indivíduo dentro do coletivo.

Nessa reunião, Mirella estava contente por noticiar-lhes que o município Campo Alegre daria início a um processo participativo nomeado Orçamento Participativo Digital (OPD), até então, novo para todos ali presentes. Por meio do Orçamento Público, a gestão municipal planeja e estima as receitas que o município pretende arrecadar e, com isso, define um limite de gastos a serem realizados com os recursos obtidos.

Surge o conceito de Orçamento Participativo (OP) como um instrumento capaz de auxiliar a eficiência dos gastos públicos e promover uma participação ativa, pois permite o debate e definição do destino dos recursos públicos, e o papel da população é essencial, pois decide as prioridades de investimentos em obras e serviços a serem realizados.

No caso específico de Campo Alegre, o mecanismo adotado seria o OPD. Este segue a mesma premissa democrática do OP, entretanto abdica da presença 100\% física dos participantes, ou seja, o processo conta com uma importante fase on-line que visa abranger ainda mais cidadãos.

Empolgada, Mirella explicava que OPD possuía potencial de estabelecer novas relações entre a sociedade e o Estado, representando, assim, uma nova dinâmica. O que para ela parecia uma ideia genial despertava nos moradores um olhar duvidoso, pois as demandas dos bairros seriam propostas de maneira coletiva, e não mais de maneira individual.

Naquele momento de desconfiança, teve ainda mais certeza de que a tentativa de fortalecer a participação social no bairro Céu aconteceria em contexto de intensa disputa de interesses particulares. Ainda que as gestões passadas assumissem posturas em que não acreditava, confiava que a população conseguiria construir um novo cenário e caminharia para mudanças positivas. E isso exigiria que parte significativa estivesse convencida de que era esse o caminho, e que a busca por interesses coletivos poderia beneficiar a todos.

\section{De volta ao passado}

O município de Campo Alegre possui 257.803 pessoas, segundo o último censo, de 2010, do Instituto Brasileiro de Geografia e Estatística (IBGE). De acordo ainda com o IBGE, estimou-se que, em 2019, a população era de 273.012 pessoas. Entre seus bairros, destaca-se o bairro Céu, que, apesar de distante dos centros comerciais, contém um número expressivo de moradores, 5.478 habitantes.

O Sr. Antônio era morador do bairro Céu desde que nascera, e seus pais, apesar das dificuldades, criaram-no com esforço e ajuda da vizinhança, que foi solícita desde a chegada de sua família por lá. Além de ser um bairro tranquilo, possui a característica de contar com moradores engajados em ajudar uns aos outros. Com o passar dos anos, Sr. Antônio fez questão de continuar morando na região, pelos laços de amizade que foram construídos, bem como para proporcionar a Mirella, sua única filha, a vivência de uma criação como a dele. 
Mirella foi uma filha-prodígio, tinha como objetivo maior os estudos e acreditava que, por meio deles, teria uma vida ainda melhor junto de seus pais. Estudou a vida inteira em escola pública, sempre como aluna de destaque e amada pelos professores. Gostava de acompanhar seu pai por onde ele ia, e os dois construíram uma relação de parceria.

Durante toda sua infância, esteve acostumada a chegar em casa depois de um dia de escola e encontrar moradores do bairro na sala de casa conversando com seus pais. O Sr. Antônio envolveuse no projeto de criar uma associação de moradores no bairro Céu. Foi o fundador e o único presidente da nomeada Amoceu.

A relação de confiança entre a comunidade e o Sr. Antônio era mútua, de modo que os desafios apresentados eram superados com uma boa conversa e uma xícara de café. Ele sempre esteve disposto a tentar resolver os problemas levantados no bairro, talvez como forma de gratidão por continuarem depositando nele as esperanças da imagem de um bom presidente, mesmo com seus erros e defeitos.

Mirella recordava-se de alguns casos curiosos que ilustravam a relação; em alguns deles, seu pai respondia que o problema remetia a uma função fora do seu alcance, mas que iria "mover seus pauzinhos" como fosse possível. Mirella observava curiosa as conversas e, certa vez, perguntou quais seriam, então, as funções de alcance do pai. Sr. Antônio pensou e respondeu:

- Ah, minha filha... Um dia você vai entender que uma mão lava a outra. O papai não pode virar as costas para os pedidos que os vizinhos fazem, pois posso precisar de um favor deles futuramente.

Entretanto, para além dos moradores, o Sr. Antônio tinha relações amistosas com os vereadores eleitos no bairro. Principalmente com Eduardo, por morarem na mesma rua. Sempre que preciso, o Sr. Antônio conversava sobre as pendências para que Eduardo conduzisse ao poder público de modo mais ágil. Mirella nunca foi muito com a cara de Eduardo, desconfiava de que ele se fazia de simpático no bairro por interesse próprio. E há quem diga que a intuição das crianças não mente.

Apesar de não entender moralmente algumas atitudes, devido à idade, Mirella via em seu pai o exemplo que queria seguir quando crescesse. Um homem adorado e que ajudava a todos o máximo que podia. Mas, com a maturidade, ela entendeu que queria mais que isso. Na época de vestibular, buscou por um curso de graduação o qual permitisse que ela se integrasse naquela sociedade com que já estava habituada para seguir o legado de seu pai.

Após sua aprovação, seguiu ativa na Amoceu para que pudesse enxergar na prática o que ela poderia ver em teoria de sala de aula. Já no primeiro período do curso de Administração Pública, esbarrou no conceito teórico chamado clientelismo. Por definição, seria uma relação de troca de favores entre o cidadão e o político ou presidente. Ela viu nisso uma explicação para o que vivenciou na gestão de seu pai, que até então não tinha nome.

Seu interesse por assumir a liderança foi tomando força, principalmente após enxergar nessa oportunidade uma maneira de oferecer à sua comunidade local uma atuação crítica e, quem sabe, inovadora. Ao mesmo tempo, sabia que o desafio teria início dentro de casa ao explanar para seu pai seu interesse em sucedê-lo.

Inicialmente, o Sr. Antônio questionou se ela estaria disposta a lidar com as dificuldades que enfrentaria, além do fato de que seria um desafio alterar a referência de liderança com que ele e moradores estavam acostumados.

\section{Presente}

Na noite após a primeira reunião, antes de dormir, Mirella refletiu sobre qual seria o melhor caminho a ser seguido. No dia seguinte, entrou em contato com a Secretaria de Planejamento, responsável pelo processo de criação do OPD no município. Durante a conversa com o secretário 
Henrique, Mirella apontou que, na Amoceu, havia uma demanda por mudança do cenário clientelista, e que isso poderia ser um empecilho para a alta participação no bairro.

Henrique marcou para o fim daquela semana uma reunião com os presidentes de Associações de Moradores do município para juntos definirem os pontos positivos e negativos que cada organização vivenciava. Para esse encontro na sexta-feira, Henrique respaldou-se nos dados do município acerca da quantidade de moradores por bairro, a fim de ter uma ideia geral do alcance que as Associações tinham.

A Amoceu, responsável pelo pedido desse debate, era um dos maiores quantitativos de moradores do município. Após a reunião, Henrique levantou a ideia de os presidentes das Associações participarem de capacitações sobre participação social, e posteriormente esse conhecimento seria repassado aos demais membros.

Mirella voltava para casa satisfeita, pois aquele primeiro debate com o secretário poderia abrir novos horizontes para a Amoceu. Mas nem tudo são flores, e o momento de "cobrar" pelo apoio recebido na eleição havia chegado. Logo ao dobrar a esquina de casa, encontrou dona Luísa, e as duas conversaram um pouco, até que dona Luísa se aproveitou da conversa para realizar um desabafo.

Aparentava estar tão abalada que Mirella a convidou para entrar em casa para as duas conversarem melhor. Contou que estava passando por um problema de enfermidade com seu marido e que, durante anos, nesses momentos de angústia, recorria a seu pai para ajudá-la. Explicou que o marido realizou diversos exames pré-operatórios por indicação do Sr. Antônio.

O problema agora era que a lista de espera para vaga na cirurgia caminhava lentamente. Nesse momento, Mirella desconfiou das intenções daquela conversa e logo se posicionou.

- Dona Luísa, eu imagino o anseio que a senhora esteja sentindo neste momento, mas não me vejo em postura de conseguir uma mudança nos critérios que a Secretaria de Saúde define para a lista de espera de cirurgias.

- Acho que você não entendeu muito bem, durante sua fala na última reunião sobre o futuro OPD de nosso município, me surgiu uma ideia. - Dona Luísa explicou.

Pontuou que tinha consciência de que seu marido precisava subir para o topo da lista, independentemente de os critérios não mudarem. Logo, a solução pensada por ela foi uma proposta de expansão da Unidade de Pronto Atendimento (UPA) do bairro.

- A ideia de expansão é interessante para nossa comunidade, você tem razão. Mas, quanto à mudança na lista, seguiria fora de nosso alcance. - Mirella respondeu.

- É aí que tá! Com a nossa UPA funcionando como Centro Cirúrgico, você e Eduardo teriam mais autonomia para que a lista daqui fosse prescrita de acordo com a necessidade dos moradores. $\mathrm{E}$ eles, com certeza, votariam em massa nessa proposta no OPD se eu pedisse. - esclareceu Dona Luísa.

Mirella, após entender que a proposta levantada por ela continha mais cunho pessoal do que público, adiantou-se em explicar que não poderia contar com o apoio dela, pois a premissa do OPD vai além de uma finalidade individual como aquela, e explicou também como não caberia a ela nem a Eduardo uma responsabilidade dessas.

Após isso, Dona Luísa disse, sem pestanejar:

- O que estou lhe pedindo seu pai faria por mim sem pensar duas vezes. Como você perdeu recentemente um ente querido, achei que entenderia meu desespero. Tenho certeza de que irá pensar em formas de me ajudar, ou então procurarei por Eduardo, que não viraria as costas neste momento.

Mirella respirou fundo e pediu que Dona Luísa a procurasse no dia seguinte na Amoceu, pois estava cansada após um dia cheio na reunião com o Secretário e não queria parecer insensível com o sofrimento por ela apresentado. 
O dia amanheceu, e Mirella caminhava até a sede da Amoceu, sem saber que as conversas correm rapidamente. Logo na entrada, foi abordada por um morador desapontado:

- Não acreditei quando ouvi que você nos deixaria na mão na primeira oportunidade, mas o vereador Eduardo estava certo. Você nunca será como seu pai, ele não negaria ajuda logo a Dona Luísa.

Mirella ficou tão surpresa com essa fala que lhe faltou uma resposta. Cumprimentou-o com a cabeça e entrou em sua sala depressa. Ela sabia que Eduardo não era a pessoa mais confiável, mas não imaginava que a comparava com seu pai pelas costas.

Ao não apoiar Dona Luísa, Mirella percebeu que o risco a correr iria além do que ela imaginava. Pelo visto, perderia totalmente o apoio e admiração dos moradores do bairro em um momento crucial, como o de fortalecimento da Amoceu para o levantamento de propostas no futuro OPD. E, é claro, perderia também a chance da reeleição que se aproximava.

Enquanto isso, a preocupação de Eduardo era se fortalecer com a comunidade, pois a eleição municipal estava ainda mais próxima. Entretanto, o apoio que Sr. Antônio deu a ele durante anos na campanha fora essencial, e agora se via numa situação em que essa troca de apoio havia se corrompido.

Na visão de Mirella, uma vez que os moradores se voltassem contra ela por não apoiar a ideia de Dona Luísa, o clientelismo impregnado no bairro se perpetuaria no processo do OPD. Em caso oposto, abriria mão de sua conquista pessoal de suceder seu pai na gestão e de agir com posicionamento baseado em princípios éticos. Com as novas eleições se aproximando e seu entusiasmo em fomentar a Amoceu em busca de dinâmicas coletivas e democráticas, que caminho deveria seguir? 